\title{
Êthos y legitimación política en los discursos de asunción de la presidente argentina Cristina Fernández de Kirchner
}

\section{$\hat{E}$ thos and political legitimization in presidential speeches of Argentinean president Cristina Fernández de Kirchner}

\author{
María Alejandra Vitale \\ Profesora adjunta, Universidad de Buenos Aires
}

Fecha de recepción: 26 de octubre de 2012

Fecha de revisión: 27 de enero de 2013

Para citar este artículo: Vitale, Ma A. (2013): Êthos y legitimación política en los discursos de asunción de la presidente argentina Cristina Fernández de Kirchner, Icono 14, volumen 11 (1), pp. 05-25. doi: 10.7195/ri14. v11i1.529 


\section{Resumen}

En el marco del análisis del discurso político que recupera la noción retórica de ethos y mediante el empleo de una metodología cualitativa, el artículo tiene el propósito de caracterizar las imágenes de sí que Cristina Fernández de Kirchner construyó en sus discursos de asunción como medio de legitimación de liderazgo político. Se trata de lo que hemos denominado ethos pedagógico-experto y, retomando análisis previos sobre el discurso presidencial de Néstor Kirchner, ethos militante. El primero responde a una escenografía profesoral donde la presidente argentina se posiciona como una profesora que da clase a sus alumnos, generada por el uso de procedimientos característicos del discurso explicativo. El ethos militante se corresponde con la violación de ciertas convenciones propias del género discurso de asunción y le permite identificarse con la figura y el gobierno de Néstor Kirchner. El ethos pedagógico-experto, por su parte, la ayuda a construir una identidad propia.

\section{Palabras clave}

Êthos - escenografía - discurso político - discurso de asunción - convenciones genéricas - liderazgo político

\section{Abstract}

Focusing on an analysis of political speech that recaptures the rhetorical concept of ethos and using qualitative methodology, this article proposes to characterize the images of self that Cristina Fernández de Kirchner developed in her speeches ascending to power as a means to legitimize political leadership. We have called this expert-pedagogical ethos and, upon reexamining previous analyses of Néstor Kirchner's presidential speeches, militant êthos.

The first category represents a professorial scenario where the Argentine president positions herself as a professor lecturing her students, presented through the use of procedures characteristic of explanatory discourse. Militant êthos corresponds to a violation of certain typical conventions of presidential speech allowing her to identify herself with the persona and government of Néstor Kirchner. The expertpedagogical ethos itself assists her in developing her own identity.

ICONO14 | Año 2013 Volumen 11 № 1 | ISSN: 1697-8293 | DOI: ri14.v1 1i1.529 


\section{Key Words}

Ethos - escenograpy - political speech - inagural speech - generic conventions political leadership

\section{Introducción}

Los discursos de asunción han despertado el interés de la crítica retórica y del análisis del discurso político por diversos motivos. En ellos los presidentes no sólo inauguran una nueva administración, anuncian un plan de gobierno y sus lineamientos ideológicos sino también construyen su propia identidad, la de su audiencia y la de sus adversarios políticos (Chumaceiro y Gallucci, 2007).

Género de la retórica presidencial que se caracteriza por la formalidad, no sólo en el plano lingüístico sino también en el protocolo social que lo acompaña (Chumaceiro, 2006; Chumaceiro y Álvarez, 2007), presenta una dimensión epidíctica que celebra valores compartidos e invita a la audiencia a evaluar las cualidades oratorias del nuevo mandatario (Campbell \& Jamieson, 2008). Asimismo, los discursos de asunción funcionan como rituales de pasaje en los que de modo performativo se configura un presidente, quien debe demostrar su capacidad de liderazgo y también su respeto a las instituciones democráticas (Dimitriu de Quintero, 2002).

El interés en los discursos de asunción se acrecienta frente a una oradora mujer que ha accedido a la presidencia por primera vez en la historia de su país, y que, además, ha sido reelecta. Este es el caso de las alocuciones de asunción pronunciadas en Argentina por Cristina Fernández de Kirchner el 10 de diciembre de 2007, día en que asumió su primer mandato presidencial, y el 10 de diciembre de 2011, cuando inició su segundo período en el poder ejecutivo.

La situación retórica de los dos discursos tuvo sus peculiaridades. Cristina Fernández de Kirchner asumió la presidencia luego de un período de cuatro años en el que su marido, Néstor Kirchner, se había desempeñado como presidente. ${ }^{1}$ Ella fue elegida candidata no mediante elecciones internas, sino por la voluntad de Néstor Kirchner, lo cual aumentaba el desafío de que demostrara que estaba a la altura de desempeñarse como primera mandataria.

Su trayectoria como diputada y senadora justicialista, y su destacado papel como opositora al (segundo) gobierno neoliberal de Carlos Menem, ${ }^{2}$ al que había 
sucedido Néstor Kirchner, incidían a favor de que contara con una imagen previa positiva. Sin embargo, el alto índice de popularidad que seguía teniendo el presidente saliente, ${ }^{3}$ la preferencia de parte de la población y del aparato del partido justicialista a favor de que él hubiese sido el candidato presidencial y la sospecha de que la candidatura de Cristina Fernández de Kirchner expresaba el proyecto oculto de que con Néstor Kirchner intentarían traspasarse indefinidamente la presidencia eran factores negativos que podían perjudicar su imagen previa al discurso de asunción de 2007. Por otra parte, a la vez que debía mostrarse como continuadora de la gestión de Néstor Kirchner, tenía que diferenciarse de ella para construir una identidad propia.

En su segundo discurso de asunción, el desafío radicaba en que Néstor Kirchner había muerto -falleció el 27 de octubre de 2010- y la presidente reelecta debía demostrar que podría gobernar sin el asesoramiento permanente de su marido. La vestimenta de Cristina Fernández de Kirchner era indicio de esta ausencia: el vestido blanco de encaje casi de una novia que llevaba cuando pronunció su primer discurso de asunción fue sustituido por el vestido negro de viuda, que no la abandonaría hasta hoy. Por otra parte, la tensión que desde la muerte de su marido se había generado con el líder de la Confederación General del Trabajo (CGT), Hugo Moyano, dejaría también sus huellas en su discurso de 2011.

Considerando lo anterior, este artículo se propone describir dos tipos de imágenes de sí preponderantes que se construyen de Cristina Fernández de Kirchner en sus discursos de asunción y que tienen la función de legitimarla en su liderazgo político. Se trata del que hemos denominado êthos pedagógico-experto (Vitale y Maizels, 2011) y del que llamamos, retomando trabajos previos sobre el discurso político de Néstor Kirchner (Dagatti, 2012; Montero, 2007), êthos militante. En lo que sigue, nos referiremos primero al estudio del êthos, luego a la metodología empleada en el análisis, a continuación describiremos el êthos pedagógico-experto y el êthos militante y finalmente presentaremos las conclusiones.

\section{El êthos en el estudio del discurso político}

Se sabe que Aristóteles fue el primero en otorgarle al êthos un lugar central en el discurso persuasivo, en cuanto lo incluye, junto al logos y al pathos, como un

ICONO14 | Año 2013 Volumen 11 N 1 | ISSN: 1697-8293 | DOI: ri14.v11i1.529 
tipo de prueba técnica, obtenida mediante el discurso del orador. En efecto, Aristóteles afirma que se persuade por medio del êthos cuando se pronuncia el discurso de tal manera que haga al orador digno de ser creído, porque a las personas buenas les creemos más y con mayor rapidez en todos los asuntos, pero principalmente en aquellos en los que no hay evidencia sino una opinión dudosa. Asimismo, Aristóteles aclara que conviene que esto suceda por medio del discurso y no porque la opinión haya anticipado este juicio sobre el orador. Walzer, Tiffany y Gross (2008) recuerdan que Aristóteles describe el êthos como un complejo tripartito que consiste en la phrónesis (sabiduría práctica), la areté (virtud moral) y la eúnoia (benevolencia). Por otra parte, destacan que la noción de êthos ha dado pie a varias controversias entre los estudiosos de la Retórica aristotélica, como el sentido exacto que les da Aristóteles a esas cualidades, el carácter moral o neutro del êthos y si la cuestión del êthos se plantea sólo en términos del discurso del orador o también en función del conocimiento previo que tiene el auditorio de su carácter. ${ }^{4}$

Los trabajos que recuperan la noción retórica de êthos en el marco del análisis del discurso retoman las propuestas de Dominique Maingueneau (1998, 1999, 2002, 2008), cuyos aportes se basan, por un lado, en la distinción entre lo que denomina êthos dicho y êthos mostrado, a partir de vincular la temática del êthos con las propuestas del lingüista francés 0swald Ducrot. En efecto, el êthos dicho corresponde a lo que Ducrot llama el locutor como $\lambda$, el locutor como ser o personaje del mundo. Se trata de los casos en los que el locutor se autorrepresenta explícitamente con ciertas cualidades; el êthos mostrado, en cambio, corresponde a lo que Ducrot denomina el locutor como tal, que es la fuente de la enunciación: se trata en este caso de un êthos implícito, una imagen que surge del orador a partir de indicadores diversos. ${ }^{5}$ Asimismo, diferencia el êthos discursivo, la imagen del orador construida por el propio discurso, del êthos prediscursivo, las representaciones del orador que posee el auditorio antes de que este tome la palabra.

Maingueneau $(1998,1999,2002,2008)$ introduce la idea de que todo êthos remite a la figura de un garante, la instancia subjetiva que es reconstruida mediante indicios discursivos por el lector y que certifica con su tono y modo de decir lo que es dicho. Plantea así la noción de incorporación para designar la manera en que la enunciación le da un cuerpo al garante, el modo en que el destinatario asimila una manera de habitar tanto su propio cuerpo como el espacio social y la constitución de un cuerpo de la comunidad imaginaria de los que adhieren a un mismo

DOI: ri14.v11i1.529 | ISSN: 1697-8293 | Año 2013 Volumen $11 \mathrm{~N}^{\circ} 1$ | ICONO14 
discurso. Por otra parte, Maingueneau ahonda en el vínculo entre la construcción del êthos y los tipos y los géneros discursivos al proponer la noción de escena de enunciación. Esta escena de enunciación es pensada en tres escenas: a) la escena englobante, que integra el texto a un tipo de discurso, por ejemplo el discurso político; b) la escena genérica, que es un contrato ligado a un genero o subgénero, como el discurso de asunción; c) la escenografía, que es la escena de habla que el texto presupone y que debe estar validada por la enunciación misma, por ejemplo la escenografía profesoral que configura Cristina Fernández de Kirchner en sus discursos de asunción.

Amossy (1999, 2000, 2001, 2010), por su parte, retoma la cuestión de si la credibilidad del orador deriva de su discurso o de su estatus social. Al respecto, recuerda que si en Aristóteles el êthos resulta de una construcción discursiva, la retórica latina, en cambio, concebirá el êthos - inspirada más en Isócrates que en Aristóteles - como algo preexistente que se apoya en la autoridad individual e institucional del orador (la reputación de su familia, su estatus social, lo que se sabe de su modo de vida, entre otros elementos). ${ }^{6}$ En relación con ello, Amossy propone analizar cómo el discurso configura un êthos a partir de datos prediscursivos previos. Retoma así la distinción entre êthos discursivo y prediscursivo, al que prefiere llamar previo, y plantea que la imagen que el orador proyecta en su discurso hace uso de datos sociales anteriores y de la imagen que de él tiene su auditorio, para que el êthos discursivo se oriente a ratificar, o, por el contrario, a modificar el êthos previo.

Específicamente en el campo del discurso político, Philippe-Joseph Salazar (2009) revisita la distinción entre las dos palabras del griego antiguo, êthos con un inicial êta ( $\tilde{\eta})$ y ethos con una inicial epsilon $(\tilde{\varepsilon})$. Son diferenciadas por un acento en transliteración, pero esta diferencia es una tensión fundamental: una designa el carácter individual, el temperamento, la moral del orador (êthos) y otra se refiere a las costumbres, el hábito social y la norma de comportamiento del grupo (ethos). Advierte que el carácter del político tiene que ser acorde a las costumbres de su auditorio y que la fabricación del acuerdo entre estos dos êthos debe ser la adecuada en función de la eficacia del discurso.

Patrick Charaudeau (2005), por su parte, realiza una tipología de las imágenes de sí que los políticos construyen discursivamente y las divide en dos grandes tipos: el êthos de la credibilidad, fundado sobre un discurso basado en la razón y en

ICONO14 | Año 2013 Volumen 11 Nº 1 | ISSN: 1697-8293 | DOI: ri14.v11i1.529 
la cualidad de ser creíble, y el êthos de la identificación, centrado en un discurso del afecto y en un proceso de identificación irracional por parte del ciudadano con el político. Charaudeau (2005: 67-68) agrega que a veces las imágenes que conforman el êthos son contradictorias entre sí y que por ello un político debe saber conciliar los contrarios. En relación con esto, Maingueneau califica al êthos de híbrido cuando las palabras de un mismo orador, en lugar de construir una única imagen dominante, mezclan más de una imagen de sí. Amossy (2010) también se refiere al êthos híbrido. Observa, por ejemplo, que Barak Obama, en su célebre discurso "A More Perfect Union" pronunciado el 18 de marzo de 2008, en relación con un auditorio compuesto (Perelman y Olbrechts-Tyteca, 1989) -es decir integrado por grupos diversos, como en este caso los electores blancos y negros-, se presenta con una identidad a la vez múltiple (hijo de padre negro de Kenya y de madre blanca de Kansas) y auténticamente norteamericana (la nación norteamericana está fundada sobre la diversidad). Al respecto, Amossy afirma que, ante un auditorio compuesto -característico de las democracias parlamentarias-, la construcción del êthos deviene una operación delicada y peligrosa en la que el candidato debe conciliar imágenes heterogéneas susceptibles de satisfacer tanto a un grupo como a otro. Por nuestra parte, hemos acuñado la noción de êthos híbrido no convergente (Vitale y Maizels, 2011) para dar cuenta de los casos en que el discurso del orador político genera más de una imagen de sí preponderante pero ellas no orientan hacia la misma conclusión. ${ }^{7}$

\section{Metodología}

Para analizar los discursos de asunción de Cristina Fernández de Kirchner hemos utilizado una metodología cualitativa (Vasilachis de Gialdino, 2006), que prioriza el interés por el significado y la interpretación, pone el énfasis en la importancia del contexto y de los procesos e implementa una estrategia inductiva y hermenéutica. Hemos focalizado el análisis de la dimensión verbal de dichos discursos, sin considerar su dimensión paraverbal (acento y entonación) y sin ahondar en indicadores no verbales (mimogestuales, proxémicos y vestimentarios).

Como sostiene Amossy $(2000,2010)$, la lingüística de la enunciación permite un primer abordaje lingüístico de la noción retórica de êthos, de allí que indagamos en

DOI: ri14.v11i1.529 | ISSN: 1697-8293 | Año 2013 Volumen 11 N 1 | ICONO14 
el uso de formas lingüísticas que expresan la deixis personal, la modalidad, ciertos actos de habla vinculados con el poder y saber de la oradora y negaciones polifónicas que manifiestan el vínculo entablando con su auditorio (Calsamiglia Blancafort \& Tusón Valls, 2007; García Negroni \& Tordesillas Colado, 2001).

En el caso del êthos que calificamos de pedagógico-experto, nos hemos basado, asimismo, en la identificación de recursos característicos del discurso explicativo descriptos por Zamudio \& Atorresi (2000), dado que la explicación es un componente fundamental del discurso pedagógico. ${ }^{8}$

Retomamos la distinción realizada por Maingueneau (1998, 1999, 2002, 2008) entre, por un lado, êthos dicho y êthos mostrado $y$, por otro, entre êthos discursivo y prediscursivo. Asimismo, recuperamos las nociones de escenografía y escena de habla. Por otra parte, nos basamos en la clasificación de Charaudeau (2005) entre los que denomina êthos de la credibilidad y êthos de la identificación. Para describir la apelación a la emoción, característica de este tipo de êthos, adoptamos la consideración clásica de la retórica de que una de las funciones de las figuras es mover los ánimos (Albaladejo Mayordomo, 1991; Plantin, 2011).

\section{Análisis}

\subsection{El êthos pedagógico-experto}

En los discursos de asunción, Cristina Fernández de Kirchner construye de sí misma la imagen de una política competente y experimentada que transmite sus saberes al auditorio. El êthos pedagógico-experto encarna una estrategia de legitimación de su liderazgo político que se corresponde con el tipo de êthos que Charaudeau llama de la credibilidad, específicamente con un subtipo que denomina êthos de la competencia, en el que el político se legitima por su formación y experiencias previas.

El êthos pedagógico-experto remite a una escena de habla en la que Cristina Fernández de Kirchner ocupa el lugar de una profesora que da clases a sus alumnos, de allí que emplee procedimientos característicos del discurso explicativo (Zamudio \& Atorresi, 2000), orientados a facilitar la comprensión por parte de los destinatarios. Esta escena de habla la ubica en una relación asimétrica con su

ICONO14 | Año 2013 Volumen 11 Nº 1 | ISSN: 1697-8293 | DOI: ri14.v11i1.529 
auditorio, en tanto la sitúa jerárquicamente en un lugar superior y de mayor poder porque posee un saber del que aquel carece.

En su primer discurso de asunción, dijimos, Cristina Fernández de Kirchner está exigida en comunicar que tiene el nivel y la autoridad para ocupar la primera magistratura de la Argentina; en el caso de su segundo discurso de asunción, el desafío radica en persuadir de que podrá gobernar sola sin el acompañamiento de Néstor Kirchner. En relación a estos desafíos, Cristina Fernández de Kirchner da de sí la imagen de una política que posee sólidos conocimientos sobre economía, lo que se construye mediante el empleo de terminología técnica como "modelo económico con matriz diversificada", "imbalances mundiales", "stock de activos financieros" o "spread de diferencias". A la vez, el uso de léxico característico de ciertas teorías (en este caso económicas) y de entidades referenciales que constituyen conceptos teóricos, como los ejemplos citados, es un aspecto distintivo del discurso explicativo (Zamudio \& Atorresi, 2000: 116-119).

Para facilitar la rápida comprensión de una noción, la presidente argentina utiliza el recurso explicativo que consiste en la paráfrasis intradiscursiva (Zamudio \& Atorresi, 2000:75), como cuando en su discurso de 2011 formula "el producto bruto global, todo lo que produce el mundo en bienes y servicios" y "la productividad de las empresas, esto es el Producto Bruto Interno dividido por cada uno de los trabajadores". Al mismo tiempo, la imagen de experta en economía se acrecienta con la apelación a indicadores estadísticos como elementos de prueba (Cussó \& Gobin, 2008), por ejemplo:

“En el año 1980, la relación entre el producto bruto global, todo lo que produce el mundo en bienes y servicios, y el stock de activos financieros, llámese bonos, derivados, lo que fuere, era del 1,1. En el año 2010, llegó a 3,4 habiendo tenido una punta en el 2006 de 3,6 veces. ¿Qué significa esto? Algo muy simple: el dinero, que es el elemento fungible por esencia para comprar bienes y servicios, hay casi 4 veces más dinero que bienes y servicios para comprar".

En la cita se observa que Cristina Fernández de Kirchner emplea preguntas polifónicas que Oswald Ducrot (1984) denomina didácticas porque el locutor expresa el punto de vista de su auditorio que no sabe la respuesta, conocida por el locutor, como cuando ella pregunta luego de referirse al aumento del stock de activos financieros “¿Qué significa esto?", para pasar a explicar ese significado.

La escenografía profesoral se construye también a través de actos de habla ma-

DOI: ri14.v11i1.529 | ISSN: 1697-8293 | Año 2013 Volumen 11 N 1 | ICONO14 
nifestados en los verbos realizativos explícitos reflexionar, corregir y recomendar. En efecto, Cristina Fernández de Kirchner, en el discurso de 2007, afirma "quiero en esta tarde y en este lugar en el que estuve tantos años reflexionar con ustedes", con lo que genera la imagen de una política en cuyo discurso el logos es protagonista. En la alocución de 2011, al referirse a una reunión pasada que compartió con el titular de la Unión Industrial Argentina en la que este expresó una opinión, la presidente aclara "yo lo corregí", posicionándose en el lugar de quien tiene la verdad y advierte el error de otro. Ese lugar del saber y de poder se observa también en ese mismo discurso cuando Cristina Fernández de Kirchner formula el acto de habla recomendar: "recomiendo, no se guíen por la letras de molde, guíense por la mirada de la gente".

El êthos pedagógico-experto y la escenografía profesoral se vinculan con la formulación de negaciones, ${ }^{9}$ que funcionan frecuentemente como corrección de palabras de otros. Por ejemplo, en el discurso de 2011 la presidente argentina sostuvo: “También la competitividad exigirá que examinemos en forma conjunta utilidades y rentabilidades para hacerlas acorde con los estándares internacionales. Esto no significa, como se dijo por ahí ninguna ley". Esta forma de negación, conocida como metalingüística, construye una imagen de sí de quien privilegia su propio punto de vista frente al que sostienen las palabras negadas de otro, en este caso no identificado explícitamente gracias al uso de la forma cuasirrefleja impersonal "se". Al negar, la oradora corrige la palabra de ese otro y es a partir de este movimiento que queda identificada con el conocimiento verdadero, en una posición asimétrica superior frente a quien es corregido y frente a su propio auditorio.

En relación con este posicionamiento y con el hecho de que en el discurso de 2011 un colaborador levantó la mano para ser identificado cuando la presidente argentina lo nombró, ella sostiene "no hace falta que levantes la mano, no soy la maestra", enunciado que expresa mediante un êthos dicho el rechazo al punto de vista atribuible a ese colaborador: ella es la maestra. Por otra parte, en su primer discurso de asunción afirma "Mi generación de eso puede dar cátedra" y en su segundo discurso sostiene "debemos aprender la lección". Los argentinos quedan así ubicados en el lugar de sujeto del aprendizaje en tanto que Cristina Fernández de Kirchner se posiciona como la profesora que les transmitirá sus saberes y cuyo poder se manifiesta en la modalidad deóntica ("Debemos"), a la vez que es mitigado con la enálage de persona (en vez de la segunda persona del plural la presidente

ICONO14 | Año 2013 Volumen 11 N 1 | ISSN: 1697-8293 | DOI: ri14.v11i1.529 
usa la primera persona del plural) porque modera la relación asimétrica (Kerbrat Orecchioni, 1986). El sintagma metafórico “los peores alumnos del grado”, asimismo, utilizado en el discurso de 2011 para representar a los argentinos luego del default de 2001, ratifica la construcción de una escenografía profesoral.

La legitimación por el saber y la experiencia inherentes al êthos pedagógico-experto se fabrican también mediante la activación, a través del êthos dicho, del êthos previo de diputada y senadora; por ejemplo, la presidente recuerda en su discurso de 2007: "Yo he pertenecido durante 12 años a este Parlamento". En este primer discurso de asunción, la primera persona del plural oscila entre una referencia máxima (yo + ustedes + ellos), que corresponde a un nosotros inclusivo con referencia "nosotros, los argentinos", y un nosotros exclusivo que tiene como referencia -en los casos en que la nueva presidente recuerda su pasado parlamentario- a "nosotros, los diputados" (yo + ellos), y a "nosotros, los kirchneristas" (yo + Néstor Kirchner y su gobierno), que le permite capitalizar a su favor lo que presenta como éxitos del gobierno de su marido, que es en ese momento el presidente saliente: "las cosas que hemos hecho en estos 4 años y medio que han sido tan importantes". En el segundo discurso de asunción, en cambio, la primera persona del plural oscila entre el "nosotros, los argentinos" y el "nosotros, los de mi gobierno", que tiende a legitimar a Cristina Fernández de Kirchner mediante la enumeración de los que presenta como logros de su período presidencial anterior: “hemos podido generar más de 5 millones de puestos de trabajo".

\subsection{El êthos militante}

La noción de êthos militante fue acuñada por Montero (2007) y retomada por Dagatti (2011) para analizar el discurso presidencial de Néstor Kirchner y dar cuenta de la recuperación de una tradición política nunca antes evocada desde la primera magistratura: la militancia revolucionaria de la década del setenta. A este êthos militante le corresponde un tipo de liderazgo que se presenta alejado de lo institucionalista y pragmático y que se muestra dotado de valores y convicciones que guían su acción. Este modo de ejercer la política se manifiesta con la capacidad de "pensar diferente" y vinculado con la transgresión contra lo instituido.

En este sentido, los discursos de asunción de Cristina Kirchner poseen similitudes con el discurso político de su marido. En efecto, en el discurso de 2007 ella

DOI: ri14.v11i1.529 | ISSN: 1697-8293 | Año 2013 Volumen 11 N 1 | ICONO14 
construye la imagen de sí de una política que tiene convicciones que guían su accionar, lo que en el nivel del êthos dicho le permite equipararse explícitamente con Néstor Kirchner cuando, refiriéndose a él, afirma: "sus convicciones que son las mías". Al mismo tiempo, se integra con Néstor Kirchner en la generación revolucionaria de los setenta mediante un êthos dicho marcado por la deixis personal de primera persona del plural (yo + Néstor Kirchner): "somos miembros de una generación que creyó en ideales y en convicciones".

En la apertura de su discurso de 2011, retoma la imagen de sí de militante de modo explícito a través del êthos dicho al afirmar: “hoy me levanté y como todas las mañanas leí los diarios, en un ejercicio militante, leer los diarios es también un ejercicio militante". ${ }^{11}$ De esa lectura, destaca como noticia que el nombre de una joven desaparecida durante la dictadura militar iniciada en $1976^{12}$ le fue puesto a un asteroide por pedido de una universidad argentina, la Universidad de La Plata, a la Unión Astronómica Mundial:

“Ustedes dirán por qué esta mención. Porque en la tapa estaba la fotografía congelada de una joven a sus veinte y pico de años. Ahora está en un asteroide su nombre. Por un momento me hizo acordar a una fotografía muy linda que apareció hace unos días de nuestra querida compañera, amiga y Presidenta de la República Federativa del Brasil, Dilma Rousseff, muy jovencita también, cuando estaba encarcelada y yo pensé por un minuto que hoy Dilma ocupa el sillón de uno de los países más importantes del mundo. A lo mejor, esta joven podría haber estado sentada en este mismo lugar en donde estoy sentada yo".

Con estas palabras, Cristina Fernández de Kirchner construye su pasado como el de una militante revolucionaria de la década del sententa. Por transitividad, dado que la foto de esta joven le recuerda a una foto de Dilma Rousseff, detenida por la policía, la presidente argentina se equipara implícitamente también con la presidente de Brasil, a quien presenta como su amiga, como un modo de legitimar su propio liderazgo político.

Según explica Montero (2007) en relación con el discurso político de Néstor Kirchner, el êthos militante evoca el valor de la juventud asociado a la lucha contra el orden establecido. Esta característica se construye en las alocuciones de asunción de la presidente argentina, con mayor intensidad en la segunda, mediante una serie de rasgos discursivos que rompen con las convenciones propias de este género de la retórica presidencial. En efecto, los discursos de asunción tienden a dar

ICONO14 | Año 2013 Volumen 11 Nº 1 | ISSN: 1697-8293 | DOI: ri14.v11i1.529 
unidad al pueblo, a construir a la audiencia como comunidad nacional, afirmando valores que la unen y evitando la polémica; además, evocan la memoria nacional (aunque siempre con un énfasis selectivo) $y$, a diferencia del discurso de campaña, no se refieren a la historia personal del presidente (Campbell \& Jamieson, 2008).

Cristina Fernández de Kirchner evoca un tramo de la historia reciente argentina sobre el que no hay pleno consenso, dado que si bien desde la transición democrática se construyó una hegemonía discursiva (Angenot, 2010) que condena la última dictadura militar y el terrorismo de Estado responsable de los desaparecidos, no sucede lo mismo respecto de la lucha armada practicada por jóvenes militantes de la década del setenta. Por otra parte, sus discursos de asunción presentan una alta dimensión polémica, como se comprueba si se comparan con los que pronunciaron las otras dos primeras mujeres presidentes de América del Sur: Michelle Bachelet, en Chile, y Dilma Rousseff, en Brasil (Vitale, 2011). En efecto, en el discurso de 2007 Cristina Fernández de Kirchner se enfrenta con Raúl Alfonsín porque promovió leyes que pusieron fin a los juicios contra los militares responsables de violación a los derechos humanos ${ }^{13}$ y con Carlos Menem a causa de su política económica neoliberal. Asimismo, se distancia de los empresarios, porque sólo buscan rentabilidad, y de los medios masivos de comunicación, que son críticos con ella. En el discurso de 2011, critica a los medios masivos de comunicación a causa de que inventan enfrentamientos en su gobierno, a los "fondos buitres" y al gobierno de Fernando de la Rúa dando a entender que tuvo una pésima actuación. ${ }^{14}$ En este segundo discurso de asunción hay otro antagonista que cobra relevancia, el líder de la CGT, Hugo Moyano, a quien la presidente no nombra de modo explícito pero alude afirmando que "con nosotros derecho de huelga hay; pero derecho de huelga, no de chantaje ni de extorsión".

$\mathrm{Si}$ al êthos pedagógico-experto le atañe una escena de habla en la que la presidente argentina se ubica en el lugar -jerárquicamente superior- de una profesora que explica, particularmente economía, a sus destinatarios-alumnos, al êthos militante le corresponde, específicamente en el discurso de 2011, una escena de habla informal extraña al género discurso de asunción que se puede caracterizar de diálogo entre amigos, en la que se atenúan las jerarquías. De esta manera, Cristina Fernández de Kirchner se dirige directamente a políticos de su partido presentes ante ella como parte del auditorio $\mathrm{y}$, por ejemplo, busca a uno preguntándole: “Calcagno, ¿dónde estás?". En relación con esta informalidad se identifica otra 
ruptura de las convenciones que rigen el discurso de asunción, en este caso el protocolo social que lo acompaña, dado que quien entregó la banda presidencial a la presidente argentina fue su hija. Como norma en la Argentina, quien entrega la banda presidencial al nuevo presidente electo es el presidente saliente, pero como Cristina Fernández de Kirchner había sido reelecta, en vez de optar por una alternativa más institucional, eligió a su hija para que le colocara la banda presidencial.

El êthos pedagógico-experto compete al tipo de êthos que Charaudeau (2005) llama êthos de la credibilidad, específicamente al subtipo denominado êthos de la competencia, donde predomina el logos; el êthos militante, en cambio, se adecua al êthos de la identificación, donde predomina el pathos. La emoción está muy ligada en el discurso de 2011 a la figura de Néstor Kirchner, a quien la presidente recuerda en el exordio y en el epílogo. En efecto, al inicio de su alocución sostiene:

“hoy no es un día fácil para esta Presidenta. Pese a la alegría y la contundencia del voto popular, falta algo y falta alguien; alguien que hace exactamente ocho años y cinco meses, en este mismo lugar que hoy estoy ocupando yo, y yo sentada frente a él, venía a decirle a todos los argentinos que él venía y pertenecía a una generación diezmada, que 30 años antes de ese 25 de mayo, había estado junto a cientos de miles en esta misma Plaza de Mayo vitoreando y festejando también la llegada de otro gobierno popular luego de 18 años de proscripciones".

Cristina Fernández de Kirchner alude aquí a los 18 años de proscripción que sufrió el movimiento peronista desde que Juan Domingo Perón fuera derrocado por un golpe militar en 1955, hasta que pudo volver al poder en 1973, aunque en un primer momento con otro candidato que no fuera Perón. Al recordar lo que dijo Néstor Kirchner cuando asumió la presidencia, el 25 de mayo de 2003, ante su mujer sentada frente a él como parte del auditorio, Cristina Fernández de Kirchner se refiere a "otro gobierno popular", con lo que identifica implícitamente el gobierno de Néstor Kirchner con el que asumió el 25 de mayo de 1973, encabezado por Héctor Cámpora, figura reivindicada por la izquierda peronista. A su vez, ella se ubica en el lugar de su marido, con lo que construye desde el inicio una imagen de sí involucrada en ese linaje político de izquierda, a partir del que el pathos cobra peso gracias a la antítesis entre la "alegría", el "vitoreando" y el "festejando", por un lado, y la connotación de la tristeza y la muerte dada por "falta algo y falta alguien", por el otro. Asimismo, la emoción es generada con figuras basadas en la repetición, como la epanadiplosis ("alguien; alguien", "ocupando yo, y yo"), el

ICONO14 | Año 2013 Volumen 11 N 1 | ISSN: 1697-8293 | DOI: ri14.v11i1.529 
paralelismo ("en esta misma plaza"/"en este mismo lugar") y la anáfora ("falta algo y falta alguien").

En el epílogo de este discurso de 2011, Cristina Fernández de Kirchner vuelve a recordar a su marido y ex presidente representándolo como un mártir que por no haber abandonado sus convicciones no cuidó su salud y dejó la vida:

"Para finalizar, yo les prometo a ustedes, mis compañeros y compañeras, y a los 40 millones de argentinos, y a todos los compañeros de la patria grande también -como dijo él- que no iba a dejar las convicciones en la puerta de la Casa de Gobierno y no las dejó, y no solamente no las dejó, sino que por no dejarlas dejó la vida."

La imagen de sí que cierra el segundo discurso de asunción de Cristina Fernández de Kirchner corresponde al êthos militante, que tiende a legitimarla en su liderazgo político mediante la identificación con Néstor Kirchner, ${ }^{15}$ a la vez que tiende a generar emoción en particular mediante el empleo de la antanaclasis ("por no dejarlas dejó la vida").

\section{Conclusiones}

Con la función de legitimación de su liderazgo político vinculado con los desafíos inherentes a las situaciones retóricas en las que produjo sus discursos de asunción, Cristina Fernández de Kirchner configuró en ellos, por un lado, un êthos que calificamos de pedagógico-experto. Este êthos se corresponde con el tipo de êthos que Charaudeau denomina de la competencia, en el que predomina el logos y en el que el político se legitima por sus saberes y experiencias. En la configuración de este êthos se destaca el empleo de ciertos procedimientos característicos del discurso explicativo. A la vez, está vinculado con una escena de habla en la que Cristina Fernández de Kirchner se posiciona en el lugar de una profesora que explica y da clase a un auditorio ubicado en el lugar de sus alumnos. Por otra parte, la presidente argentina legitima su liderazgo mediante la construcción de un êthos que calificamos de militante porque recupera la militancia revolucionaria de la década del sententa y se presenta con convicciones que llevan a cuestionar el orden establecido, lo que a nivel discursivo se expresa en la violación de ciertas convenciones que rigen el género de la retórica presidencial discurso de asunción.

DOI: ri14.v1 1i1.529 | ISSN: 1697-8293 | Año 2013 Volumen 11 No 1 | ICONO14 
Este êthos militante corresponde al tipo de êthos que Charaudeau denomina êthos de la identificación, en el que predomina el pathos.

Estas dos imágenes de sí, que se adecuan a segmentos no siempre coincidentes de un auditorio compuesto característico de las democracias representativas, resultan complementarias. En efecto, se trata de la construcción de un êthos híbrido que puede ser calificado de convergente, dado que tanto el êthos pedagógicoexperto como el êthos militante se orientan a legitimar el liderazgo político de la presidente argentina. Por otra parte, subyace en ambos un valor común que es el saber y la verdad de los que son poseedoras la profesora y la militante, dueña de convicciones que guían su acción política. Cristina Fernández de Kirchner se posiciona así en el lugar de un saber y de una verdad sin fisuras, que la legitimarían como presidente tanto en relación a la situación de su primer mandato como la del segundo. Si el êthos militante la equipara a Néstor Kirchner y la ayuda a presentarse como continuación de su gestión, el êthos pedagógico-experto le permite adquirir una identidad propia.

El êthos pedagógico-experto y el êthos militante han formado parte del estilo del discurso político posterior de Cristina Fernández de Kirchner y están vinculados, respectivamente, a cuestionamientos sobre su soberbia y tono confrontativo y polémico. ${ }^{16}$ De allí que un estudio sobre la recepción de los discursos de asunción de la presidente argentina, en particular en la prensa escrita, se vislumbra como una tarea estimulante que complemente el análisis realizado en este trabajo.

\section{Notas}

[1] Néstor Kirchner (1950-2010) fue presidente de Argentina desde 2003 a 2007. En 2003, accedió a la presidencia encabezando el Frente para la Victoria, nombre de una alianza electoral integrada, entre otros, por sectores del Partido Justicialista (PJ) y de la Union Cívica Radical (UCR), el Partido Comunista (PC) y el Partido Humanista (PH). Dicha alianza presentó la fórmula Cristina Kirchner-Julio Cobos (proveniente de la UCR) para las elecciones presidenciales de 2007 y la fórmula Cristina Kirchner-Amado Boudou para las elecciones presidenciales de 2011.

[2] Carlos Saúl Menem se desempeñó como presidente durante dos períodos consecutivos: 19891995 y $1995-1999$.

[3] Sobre la popularidad de Néstor Kirchner y el proceso electoral de 2007, ver Gallo (2008).

ICONO14 | Año 2013 Volumen $11 \mathrm{~N}^{\circ} 1$ | ISSN: 1697-8293 | DOI: ri14.v11i1.529 
[4] Sobre las controversias vinculadas con la noción de êthos en Aristóteles, ver también Smith (2004).

[5] Catherine Kerbrat Orecchioni (2008, 2010), por su parte, destaca que estos indicadores son multimodales, pues son verbales, paraverbales (acento y entonación) y no verbales (mimogestualidad, proxemia y vestimentas); asimismo, considera que son polisémicos, dado que su valor se determina solo en el contexto y en su interpretación interviene siempre en parte la subjetividad.

[6] Aristóteles hace hincapié en el estatuto discursivo del êthos, porque la imagen del orador y su credibilidad no dependen de sus cualidades extradiscursivas ni del juicio previo del auditorio. Ello quedaría claro cuando explicita que conviene que la credibilidad del orador se alcance por medio del discurso y no porque la opinión haya anticipado este juicio respecto del orador. En este sentido, Aristóteles se aparta de sus antecesores, específicamente de Platón (Gorgias) e Isócrates (Antídosis), quienes destacaron la influencia que ejercen la vida real del orador y su consideración social sobre la fuerza persuasiva de su discurso, de modo que si un orador es una persona de carácter irreprochable, sus opiniones serían admitidas con mayor facilidad, pues nada malo se puede esperar de él. Sobre el carácter discursivo del êthos en Aristóteles, ver Woerther (2007) y Vitale (2012).

[7] El discurso electoral de 2007 de Cristina Fernández de Kirchner, proferido en un contexto en el que se debatía en Argentina si ella o Néstor Kirchner debían ser el candidato presidencial, construyó, por un lado, la imagen de una política experimentada y competente, que orientaba a favor de su candidatura presidencial pero, por otra parte, configuró la imagen de víctima que por ser mujer todo le resultaría más difícil, lo que no orientaba a favor de dicha conclusión (ver Vitale y Maizels, 2011).

[8] Resulta por eso pertinente recuperar el sentido interaccional de la explicación como "enseñar", "hacer saber" o "hacer comprender" (Zamudio \& Atorresi, 2000: 10).

[9] Para un estudio de las negaciones en el discurso electoral de 2007 de Cristina Fernández de Kirchner, ver Maizels (2011).

[10] Según García Negroni (1998), la negación metalingüística, que opone dos locutores diferentes o un mismo locutor en momentos diferentes, siempre es descalificadora de un marco de discurso previo y tiene la función fundamental de instaurar un nuevo espacio de discurso, presentado por el locutor como el único adecuado para la caracterización argumentativa de la situación de la que habla.

[11] Las afirmaciones de Cristina Fernández de Kirchner se comprenden contemplando que fueron proferidas en una situación retórica signada por el enfrentamiento de su gobierno con el multimedios dueño del diario Clarín, el de mayor tirada en la Argentina.

[12] La última dictadura militar que sufrió Argentina se desarrolló desde 1976 a 1983. 
[13] Cristina Fernández de Kirchner se refiere de modo negativo a las leyes $\mathrm{N}^{\circ} 23.492$ de Punto Final y No 23.521 de Obediencia Debida, aprobadas por el Congreso argentino en 1986 y 1987, respectivamente. Raúl Alfonsín (1927-2009), la Unión Cívica Radical, se desempeñó como presidente de la Argentina desde 1983 a 1989.

[14] Fernando de la Rúa se ejerció como presidente de Argentina desde 1999 a 2001, cuando renunció a causa de una aguda crisis económica y social. Había asumido como representante de una Alianza entre el Partido Radical y sectores del Partido Justicialista enfrentados con Carlos Menem.

[15] La enálage personal, "esta Presidenta", tiende, asimismo, a posicionar a Cristina Fernández de Kirchner con autoridad (Kerbrat Orecchioni, 1986).

[16] El jefe de la Confederación General del Trabajo, Hugo Moyano, por ejemplo, criticó de la presidente argentina su "intelectualismo" y su soberbia. Ver http://www.cadena3.com/contenido/2012/07/27/100747.asp y “De Moyano a Cristina: 'No actúe con soberbia'", Clarín, 15-9-12, p. 1.

\section{Referencias}

Albaladejo Mayordomo, T. (1991). Retórica. Madrid: Síntesis.

Amossy, R. (Comp.). (1999) Images de soi dans le discours. La construction de l'ethos. Paris: Delachaux et Niestlé.

Amossy, R. (2000). L'argumentation dans le discours politique. Litterature d'idée, fiction. Paris: Nathan.

Amossy, R. (2001). Ethos at the crossroads of disciplines: Rhetoric, Pragmatics, Sociology, Poetics Today, 22, 1-23.

Amossy, R. (2010). La présentation de soi. Ethos et identité verbale. París: PUF. Angenot, M. (2010). El discurso social. Los límites de lo pensable y lo decible. Buenos Aires: Siglo XXI.

Campbell, K. \& Jamieson, K. H. (2008). Presidents creating the presidency. Deeds done in words. Chicago: The University of Chicago Press.

Charaudeau, P. (2005). Le discours politique: les masques du pouvoir. Paris: Vuibert.

Chumaceiro, I. (2006). Bolívar en la toma de posesión de tres presidentes venezolanos. En M. Sedano, A. Bolívar \& M. Shiro (Comp.), Haciendo lingüística. Homenaje a Paola Bentivoglio (pp. 645-658). Caracas: Comisión de Estudios de Posgrado, Facultad de Humanidades y Educación, Universidad 
Central de Venezuela.

Chumaceiro, I. \& Álvarez, A. (2007). El discurso de investidura en la reelección de Uribe y Chávez. Actas del VII Congreso Latinoamericano de Estudios del Discurso ALED, Bogotá, 91-97.

Chumaceiro, I. \& Gallucci, M. J. (2007). La noción de democracia en los discursos de toma de posesión de Hugo Chávez y Álvaro Uribe. Actas del VII Congreso Latinoamericano de Estudios del Discurso ALED, Bogotá, 98-107.

Cussó, R. \& Gobin, C. (2008). Du discours politique au discours expert: le changement politique mis hors débat? Mots. Les langages du politique, 88, 5-11.

Dagatti, M. (2012). El estadista oculto. El ethos gubernamental en los discursos públicos presidenciales de Néstor Kirchner. Rétor 2(1), 55-93. Recuperado de http://www.revistaretor.org/pdf/retor0201_dagatti.pdf

Dimitriu de Quintero, M. (2002). Rituales discursivos en la toma de posesión del ex presidente de Venezuela Rómulo Betancourt, Núcleo, 19, 57-69.

Ducrot, 0. (1984). El decir y lo dicho. Buenos Aires: Hachette.

Gallo, A. (2008). Reelección inmediata y sucesión en clave matrimonial. Análisis del recambio presidencial argentino de 2007. Espacios públicos, 11 (23), 168-199.

García Negroni, M. M. (1998). La negación metalingüística: argumentación, gradualidad y reinterpretación. Signo y Seña, 9, 227-252.

García Negroni, M. M. \& Tordesillas Colado, M. (2001) La enunciación en la lengua. De la deixis a la polifonía. Madrid: Gredos.

Kerbrat Orecchioni, C. (1986) La enunciación. De la subjetividad en el lenguaje. Buenos Aires: Hachette.

Kerbrat Orecchioni, C. (2008). A construção mútua das identidades nos debates políticos na televisão. En G. Muniz Proença Lara, I. L. Machado \& W. Emediato (Ed.), Análises do discurso hoje (pp. 235-264), vol. 2. Río de Janeiro: Ed. Nova Fronteira.

Kerbrat Orecchioni, C. (2010). 0 ethos em todos os seus estados. En I. L. Machado \& R. de Mello (Ed.), Análises do discurso hoje (pp. 117-135). vol. 3. Rio de Janeiro: Nova Fronteira.

Maingueneau, D. (1998). Analyser les textes de communication. Paris: Dunod. Maingueneau, D. (1999) Ethos, scénographie, incorporation. En R. Amossy, 
Images de soi dans le discours. La construction de l'ethos (pp. 75-100). Paris: Delachaux et Niestlé.

Maingueneau, D. (2002). Problèmes d'ethos. Pratiques, 113/114, 55-67. Maingueneau, D. (2008). A propósito do ethos. En R. A. Motta \& L. Salgado (Comp.) Ethos discursivo (pp. 12-29). São Paulo: Editora Contexto. Maizels, A. L. (2007). Negación, "otras voces" y ethos. Un análisis de los discursos de campaña política de Cristina Fernández de Kirchner, RILL, 17 (1/2), 1-11. Recuperado de http://www.insil.com.ar/adminis/up-load/ upload/rill2012/Art\%C3\%ADculo\%2011\%20MAIZELS,\%20Ana.pdf

Montero, A. S. (2007). Política y convicción. Memorias discursivas de la militancia setentista en el discurso presidencial argentino. ALED, 7 (2), 92114.

Perelman, Ch. \& Olbrechts-Tyteca, L. (1989). Tratado de la argumentación. La nueva Retórica. Madrid: Gredos.

Plantin, Ch. (2011). Les bonnes raisons des émotions - Principes et méthode pour l'étude du discours émotionné. Paris: Peter Lang.

Salazar, Ph.-J. (2009). L'hyperpolitique. Une passion française. Paris: Klincksieck. Smith, C. R. (2004). Ethos Dewlls Pervasively. A Hermeneutic Reading of Aristotle on Credibility, en M. J. Hyde (Ed.) The Ethos of Rhetoric. Columbia: University of South Carolina Press.

Vasilachis de Gialdino, I. (Coord.) (2006). Estrategias de investigación cualitativa. Barcelona: Gedisa.

Vitale, M. A. \& Maizels, A. L. (2011). El discurso electoral de Cristina Fernández de Kirchner (2007). Un caso de ethos híbrido no convergente. Linguagem em (Dis)curso, 11 (2), 337-360.

Vitale, A. (2011). La construcción del êthos en los discursos de asunción de Michelle Bachelet, Cristina Kirchner y Dilma Rousseff, conferencia dictada en el I Congreso Internacional de Retórica, Universidad Nacional de Rosario, 13, 14 y 15 de octubre.

Vitale, M. A. (2012). La noción de ethos. De la Antigua Retórica al Análisis del Discurso. En P. da Cunha Corrêa, M. Martinho, J. M. Macedo y A. Pinheiro Hasegawa (Ed.), Hyperboreans. Essays in Greek and Latin Poetry, Philosophy, Rhetoric and Linguistics (pp. 217-232). São Paulo: Humanitas.

Walzer, A., Tiffany, M. \& Gross, A. G. (2008). Aristotle's Rhetoric: a guide to the 
scholarship. En Gross, A. \& A. E. Walzer, Rereading Aristotle’ Rhetoric (pp. 185-203). Carbondale: Sothern Illinois University Press.

Woerther, F. (2007). L'êthos aristotélicien. Genèse d'une notion rhétorique. Paris: Vrin.

Zamudio, B. \& Atorresi, A. (2000). La explicación. Bs. As.: EUDEBA. 